\title{
Does the ethical appropriateness of paying donors depend on what body parts they donate?
}

Erik Malmqvist

\author{
Linköping University Post Print
}

\section{Tweet}

N.B.: When citing this work, cite the original article.

The original publication is available at www.springerlink.com:

Erik Malmqvist, Does the ethical appropriateness of paying donors depend on what body parts they donate?, 2016, Medicine, Health care and Philosophy, (19), 3, 463-473.

http://dx.doi.org/10.1007/s11019-016-9705-6

Copyright: Springer Verlag (Germany)

http://www.springerlink.com/?MUD=MP

Postprint available at: Linköping University Electronic Press

http://urn.kb.se/resolve?urn=urn:nbn:se:liu:diva-130715 


\title{
DOES THE ETHICAL APPROPRIATENESS OF PAYING DONORS DEPEND ON WHAT BODY PARTS THEY DONATE?
}

\author{
Erik Malmqvist, Linköping University \\ erik.malmqvist@liu.se
}

Please cite the final version: Malmqvist, E. Does the ethical appropriateness of paying donors depend on what body parts they donate? Medicine, Health Care and Philosophy 2016;19(3): 463-473.

\begin{abstract}
The idea of paying donors in order to make more human bodily material available for therapy, assisted reproduction, and biomedical research is notoriously controversial. However, while national and international donation policies largely oppose financial incentives they do not treat all parts of the body equally: incentives are allowed in connection to the provision of some parts but not others. Taking off from this observation, I discuss whether body parts differ as regards the ethical legitimacy of incentives and, if so, why. I distinguish two approaches to this issue. On a "principled" approach, some but not all body parts are inherently special in a way that proscribes payment. On a "pragmatic" approach, the appropriateness of payment in relation to a specific part must be determined through an overall assessment of e.g. the implications of payment for the health and welfare of providers, recipients, and third parties, and the quality of providers' consent. I argue that the first approach raises deep and potentially divisive questions about the good life, whereas the second approach invokes currently unsupported empirical assumptions and requires difficult balancing between different values and the interests of different people. This does not mean that any attempt to distinguish between body parts in regard to the appropriateness of payment necessarily fails. However, I conclude, any plausible such attempt should either articulate and defend a specific view of the good life, or gather relevant empirical evidence and apply defensible principles for weighing goods and interests.
\end{abstract}

\section{Introduction}

Financial payment to donors (or providers ${ }^{1}$ ) is sometimes used or advocated as a way of meeting the growing demand for human bodily material for therapy, assisted reproduction, and biomedical research. Such payment is, however, widely considered ethically problematic. It is reasonable to assume that this unease about money partly reflects the view that the human body is special. Unlike cars or chocolate bars it is not an appropriate object of market exchange. Our bodies should not be treated as commodities, as the slogan goes. Many people appear to hold this view, albeit for different reasons. However, it is seldom asked whether the

\footnotetext{
${ }^{1}$ I will henceforth use the term 'provider' rather than 'donor', which has connotations to altruism that may be misleading when money is offered in exchange for what is provided.
} 
purported special status of the body applies equally to all its parts, or whether, instead, there are differences between body parts in regard to the appropriateness of paying providers. ${ }^{2}$

A quick glance at the international policy landscape suggests that such differences, while rarely articulated and defended, are nonetheless implicitly assumed to exist. While financial rewards to organ providers are almost universally illegal (Iran currently being the only exception), there are a number of jurisdictions that permit such rewards in connection to the provision of eggs, sperm, blood, plasma, and/or bone marrow. ${ }^{3}$ Sometimes international policies on reimbursement and/or compensation to providers are subject to different interpretations, permitting a higher degree of commercialization in some countries than in others. Consider, for instance, the EU Tissues and Cells Directive's provision that reimbursement be "strictly limited to making good the expenses and inconveniencies related to the donation" (2004/23/EC, Article 12). In Spain this provision is considered consistent with offering egg providers sums that many regard as de facto financial incentives, while other European countries only permit more modest fees (Cooper and Waldby 2014). Moreover, even in countries with restrictive policies on payment in relation to these body parts, there are others, such as hair and nail clippings, the paid exchange of which is not (usually) subject to any regulation at all.

This rather variegated policy situation raises the following questions. Does the ethical legitimacy of paying donors systematically differ depending on what body parts are involved? And if there are such differences, what is their justification? These are the questions I will discuss in this paper. My aim is not to provide a complete and conclusive set of distinctions between body parts in regard to the appropriateness of payment (nor even to establish whether payment in relation to any particular part is acceptable), but only to identify some dimensions along which such distinctions can be drawn. I am specifically interested in distinctions capable of justifying differential policies on payment rather than moral distinctions in general.

\footnotetext{
${ }^{2}$ Thus, while scholarly debates about paid donation revolve around something like what Eyal calls "body exceptionalism", i.e. "the view that we should treat the body...differently than we do material resources" (Eyal 2009: 234), there has been little attention in this context to what we might call "body parts exceptionalism", i.e. the view that certain (but not all) parts of the body warrant such treatment.

${ }^{3}$ These include Spain, Greece, and Ukraine (eggs), Germany (blood), and several states in the US (eggs, sperm, plasma, and bone marrow) (Almeling 2011, NCoB 2011, Williams 2011, Pennings et al. 2014, Harvey 2015). By 'reward' I mean payment that (de facto or de jure) "goes beyond 'recompensing' the person for the losses incurred in donating" ( $\mathrm{NCoB} 2011: 70)$.
} 
Also, I am interested in distinctions that are systematic or general in the sense that they support such policies across socioeconomic, cultural, and institutional contexts. ${ }^{4}$

I shall limit the scope of my inquiry in four ways. First, when I speak of body parts I mean discrete physical entities - organs, cells, tissues, and fluids. I will not discuss "bodily services" such as surrogacy and participation in clinical research. This delimitation is mainly pragmatic: although it is unclear that payment for such services ultimately differs ethically from paid donation (NCoB 2011, Malmqvist and Zeiler 2016), including them would make the discussion intractably complex. Second, whereas money may be involved at different stages between the acquisition of body parts and their use by the final beneficiaries, I will focus on payment to providers. Third, I will focus on living providers and thus not discuss payment in the cadaveric donation context (whether to relatives or to prospective donors themselves). Fourth, whereas payment may have different forms and functions (NCoB 2011), I will focus on payments that constitute positive incentives. In other words, I will limit my discussion to payments that motivate those who would not otherwise be inclined to donate by promising a net financial gain. This excludes reimbursement of financial costs incurred as a result of donating (e.g. travel expenses, lost income), but includes payments beyond this level, whether in the form of a monetary sum or a discount (e.g. "egg sharing" [Roberts and Throsby 2008], tax brakes). Payment intended as compensation for time and inconvenience is difficult to categorize because it may (as the case of Spain illustrates) in fact work as a positive incentive for donors of modest means. When it functions, or can reasonably be assumed to function, in this way I include it as well - the intention notwithstanding.

Related to this last issue, I will assume throughout my discussion that financial incentives are effective - i.e. that they motivate providers sufficiently to make more body parts available. This assumption is far from unquestionable. A standard concern about paying providers is that doing so may discourage unpaid donation, causing an overall decrease in supply (Titmuss 1970, Rothman and Rothman 2006) - a concern that is supported by a large body of empirical evidence showing that financial incentives can have unexpected effects and even be counterproductive (e.g. Gneezy and Rustichini 2000). However, while I certainly do

\footnotetext{
${ }^{4}$ Thus, my argument is located at a somewhat higher level of abstraction than analyses of the ethics of payment in relation to specific body parts typically are. But it is less abstracted than Fabre's (2006) excellent exploration of the status of the body in "ideal theory", where it is assumed that agents fully comply with the demands of justice. By contrast, my discussion explores ethical quandaries arising in our current, decidedly non-ideal world.
} 
not want to dismiss this concern, I will bracket it for present purposes. For if incentives to providers turn out to be ineffective the main rationale for introducing them disappears, and the other issues concerning their appropriateness that I want to discuss become largely moot.

\section{Two approaches}

Some may wish to deny that the legitimacy of payment varies depending on what body part is provided. It might be argued that payment is always illegitimate, perhaps because it inevitably degrades the persons from which body parts are acquired. Or it might be argued, conversely, that my body is my property, and that I may therefore do whatever I please with its parts, including alienating any and all of them for money. ${ }^{5}$ However, if we want to take the heterogeneous policy situation outlined earlier seriously, rather than dismissing it as inconsistent from the outset, we must set these positions aside and leave open the possibility that there are morally relevant distinctions to be drawn here.

It is useful to distinguish between two general ways in which we can begin drawing such distinctions. On a "pragmatic" approach body parts should be treated differently insofar as this is warranted by a concern for the health and welfare of providers, recipients, and third parties, and for the quality of providers' consent. To determine whether payment for a particular part is appropriate we need to consider, for instance, the need or demand for that part; the likelihood that the choice to provide it is sufficiently informed and voluntary; the risks and burdens that payment may entail for providers and recipients; and the effects of payment on social norms, practices, and institutions. Moreover, if these considerations conflict, we must weigh them against each other. On a "principled" approach certain body parts are inherently special in a way that makes payment in connection to their provision inappropriate, regardless of the consequences for the affected parties and even when providers genuinely consent. Other body parts lack this special status and are therefore not in principle non-commodifiable.

These approaches are not mutually exclusive. We may take one approach with respect to certain body parts and the other approach with respect to others. Nor is it strictly inconsistent to adopt both perspectives with respect to one single part, and so resist its commodification for both pragmatic and principled reasons - although pragmatic

\footnotetext{
${ }^{5}$ Kant is sometimes attributed the first of these views because of his condemnation of all bodily commodification (including of hair and teeth) in his Lectures on Ethics (1997a), but it is debatable whether this condemnation reflects his philosophy or the prejudices of his time. Andrews (1986) provides a robust defence of the view of the body as personal property, but stops short of endorsing the commodification of all its parts.
} 
considerations seem somewhat superfluous if payment is wrong "no matter what". Indeed, such a dual view sometimes surfaces in policies in this area. In its guiding principles on therapeutic organ, tissue, and cell donation, which explicitly exclude reproductive donation and the acquisition of blood for transfusion, the WHO (2010) states that payment both "undermines altruistic donation" (reflecting a pragmatic concern) and "conveys the idea that some persons lack dignity, that they are mere objects to be used by others" (reflecting a more principled concern). But even though these approaches tend to intermingle it is important to keep them apart. For, as we shall see, the reasons why body parts are distinguished matter to how responsive the distinctions are to changing circumstances and growing knowledge.

The pragmatic approach, broadly construed, is familiar and fairly uncontroversial: considerations about health, welfare, and consent figure prominently not only in scholarly and policy debates about donation but also in everyday moral thought and practice more generally. This does not mean that this approach is straightforward once we start working out the details - far from it, I shall suggest. Nonetheless, I will first examine the principled approach because it appears, on the face of it, more contentious and less familiar.

\section{Which body parts are special, and why?}

The most straightforward principled case against commodifying the human body in general rests on three assumptions. First, persons are not things. They must not be instrumentalized, or, as Kant (1997b) famously put it, never be treated as mere means but always also as ends in themselves. Second, to treat something as a commodity is to instrumentalize it (Nussbaum 1995). Third, bodies are essential to persons. I am my body, as phenomenological philosophers are fond of putting it (Merleau-Ponty 2002). Therefore, treating a person's body as a commodity amounts to wrongfully instrumentalizing the person herself.

Now this view, stated in such a general way, does not distinguish between different parts of the body. No such part ought to be bought or sold. To get at a more nuanced view we must relax the third assumption, so that some but not all body parts are taken to be essential to persons. But which parts? And what makes these parts essential? Let us look at a couple of different answers to these questions.

\section{Personal identity}

One approach is to single out the parts of the body that matter most to personal identity. Sveneaus $(2012,2015)$ has recently provided detailed phenomenological analyses of the connections between different transplantable body parts and the identity of those who provide 
or receive them. More precisely, proceeding from the first-person perspective of lived experience, Svenaeus argues that different body parts have different meaning and importance for us as embodied creatures who feel, perceive, act, and interact in a shared and culturally constituted world. How closely connected body parts are to personal identity depends on several factors, he suggests, including whether they can be directly felt (as hearts can but kidneys cannot); their visibility and role in self-expression and communication (hands and faces are salient here); their importance for agency (think of limbs and brains); and, not least, the symbolic qualities they are invested with by science and culture (think of hearts, blood, and genes). Svenaeus also argues that this analysis has implications for the ethical acceptability of commodification: the more intimately connected a body part is to personal identity, the stronger the case against treating it as a good on a market (Svenaeus 2015).

I have no doubt that certain body parts are more important than others to personal identity for the reasons that Svenaeus provides. However, the ethical and, in particular, policy implications this observation do not seem straightforward. First, the connection between body parts and personal identity is likely to vary significantly between persons. Some people identify much more strongly with, say, their hands than others. The same goes for hearts, kidneys, eyes, hair, and so on. This is not to deny that there are general patterns here: we all live in a culture that attributes symbolic significance to the hand, and most of us depend on our hands for self-expression and communication. The point is rather that individuals take up, modify, and emphasize or downplay these general patterns in different ways depending on their particular life histories and personal circumstances. For instance, the significance of the hand is heightened and refined in the case of an actor who excels in using its expressive and symbolic qualities in her work. It is plausible to say that her hand is more central to her identity than hands are to the identities of people in general. This individual variability makes it difficult to use the connection between body parts and personal identity as a basis for distinguishing between body parts on a policy level. Presumably policies that regulate payment must apply equally to everyone.

Second, since the connection between body parts and personal identity is partly culturally constituted, it is also likely to reflect cultural prejudice. It does not seem unlikely that many women identify more strongly than many men with their hair and other visible physical features because our culture expects women to be more preoccupied than men with their physical appearance - an expectation that many feminists rightly criticize. Nor does it seem far-fetched to think that many women identify more strongly with their eggs than many men do with their sperm because our culture has traditionally confined women to the 
reproductive sphere. ${ }^{6}$ If we then take women's stronger identification with their reproductive cells as justification for prohibiting payment to egg donors while allowing payment to sperm donors, our policy would be partly based on a dubious social norm. It would also lend this norm legitimacy and thus arguably help perpetuating it. It may be the right policy, but its basis and expressive significance seem questionable.

\section{Human functioning and human flourishing}

These reflections may lead us to attempt to define which body parts are special in a way that is less amenable to individual variation and cultural prejudice. This, in turn, seems to require a more explicitly normative concept than personal identity - i.e. a concept that better explains why certain body parts ought to be regarded as special rather than why they in fact are so regarded. Cohen invokes the notion of human functioning for this purpose:

[O]ur special value as human beings extends to our bodies. Yet it does not extend to all parts of our bodies. We do not ordinarily consider that hair, spit, or fingernail parings carry human dignity and worth, for these generally function as inessential human bits and pieces unrelated to what it is that makes human beings of special value. It is those parts of the body that are integral to the functioning of human beings, such as kidneys, livers, brains, hearts, and eyes, that we take to bear special dignity and worth because of their role (Cohen 1999: 291).

It is these integral parts - among which Cohen also counts gametes, fetal reproductive tissue, the face, and any somatic cell used for reproductive cloning - that must not be bought and sold, for to commodify them "is to deny the special value of human beings" (Ibid: 292). However, the commodification of parts that are not integral to human functioning - such as "hair, spit, or fingernail parings" (Ibid: 291) - is permissible.

Now to determine more precisely which body parts are integral to human functioning and which are not, a more articulate conception of human functioning is needed. Cohen is unfortunately not very explicit about what such conception her argument relies on, but different alternatives are imaginable. It is unlikely that strict biological functioning is what

\footnotetext{
${ }^{6}$ Almeling's (2011) finding that US egg donors explicitly dissociate themselves from their eggs may seem to contradict this assumption, but this dissociation is more reflective of the interests and rhetoric of egg agencies than of some general cultural pattern of identification.
} 
she has in mind. All (or nearly all) parts of our bodies - including hair, spit, etc. - presumably have some biological function, i.e. play some functional role at some level of organization of our biological organism. Therefore, a strict biological conception does not seem to provide us with any way of distinguishing between different body parts.

We might instead understand human functioning in terms of some purpose or goal that human beings have merely in virtue of being human. Such ideas of an ultimate human purpose were congenial to the ancient Greeks. Plato, for instance, thought that this purpose was to attain perfect knowledge. Similarly, different religious traditions incorporate different ideas about an ultimate human purpose - to reverence and serve God, to attain salvation or afterlife bliss, and so forth. However, in a pluralistic and secularized society the idea that there is some single goal or purpose for human beings as such is likely to strike many of us as unattractively archaic or metaphysical. We are more inclined to believe that people have different goals, the content of which they (partly) set for themselves.

I believe the most plausible way of understanding Cohen's appeal to human functioning is broadly Aristotelian. For Aristotle (1980), our function as humans is eudaimonia, which can be roughly translated as "flourishing", "happiness", or "wellbeing". He believed that this is both what we naturally pursue and what is ultimately good for us. While many today would reject the idea of a natural human purpose along with the rest of Aristotle's metaphysics, the idea of human flourishing is one that we retain, in some form or other. We still believe that people's lives can go better or worse, be more or less fulfilled, even though we doubt that lives naturally tend towards the good. Thus, human functioning can be understood neither in biological terms nor in terms of some metaphysically or religiously defined goal, but instead in terms of the necessary elements of a genuine or good human life. To function in this sense is to be and do what is distinctly human, normatively speaking, and to function well is to flourish or live a good human life (Nussbaum 1992).

This conception of human functioning suggests a way of distinguishing between body parts that are essential to persons and body parts that are not. The essential parts, the parts that should be kept out of the stream of commerce, are those that play some important role in regard to human flourishing - i.e. that enable or facilitate the attainment of some state or the performance of some activity that is constitutive of or instrumentally important for a good life. It seems plausible that some such conception of human functioning underlies Cohen's argument. Part of what makes gametes special, and their sale wrong, she argues, is their role in an activity "of special import to human beings, reproduction" and their capacity to create 
"special biological, ethical, and social relation[s]" which are "[p]art of what gives meaning and cohesiveness to our lives" (Cohen 1999: 296-297).

This way of distinguishing between body parts is arguably less susceptible to individual variability and cultural prejudice than the appeal to personal identity. The crux, of course, is that defining the limits of the market requires some conception of human flourishing (Radin 1996). To say that philosophers are divided on this issue is an understatement. There is deep, age-old disagreement about whether flourishing ultimately consists in pleasurable experiences, desire satisfaction, or the attainment of a plurality of distinct objective goods, such as knowledge, rich personal relationships, and aesthetic enjoyment (Parfit 1984: Appendix I), and each alternative comes in different versions. Which body parts are essential to persons will vary greatly depending on which view on flourishing one adopts: different parts seem important for feeling pleasure than for engaging in the wide range of activities that “objective list" theorists typically consider constitutive of flourishing (Nussbaum 1992). This does not mean that this way of defining which body parts are special necessarily fails. It is extremely indeterminate, however, and any attempt to make it precise enough to guide policies on payment will require taking a stand on one of the most deeply contested questions in the history of philosophical thought. This is particularly challenging considering that such policies must apply to different people who are likely to hold substantively different views of the good life with different implications for the status of different body parts.

\section{Pragmatic reflections}

In response to the difficulties with the principled approach we might prefer to deal with the question at hand more pragmatically. On a pragmatic approach there is nothing inherently special about certain body parts that proscribes paying those who provide them. Whether or not payment in relation to a particular part is appropriate instead depends on an overall assessment of considerations such as the need or demand for the body part, risks and burdens to providers and recipients, effects on other parties, and the possibility of ensuring that providers give valid consent. Since such considerations are commonly taken to be morally relevant regardless of more fundamental religious, political, or philosophical convictions, ${ }^{7}$ this approach seems on the face of it capable of sidestepping the deeply contested questions

\footnotetext{
${ }^{7}$ Some such idea underlies the familiar "four principles" approach to bioethics (Beauchamp and Childress 2012), for instance. Largely on the basis of what I here call pragmatic considerations, this approach seeks to articulate ethical principles that people can in principle agree on despite deep normative and metaphysical disagreements.
} 
about the good life that the principled approach raised. In this section I shall discuss several such pragmatic considerations in order to determine whether they can justify distinctions between body parts in regard to the appropriateness of payment. ${ }^{8}$

\section{Demand}

There is an unmet demand for many kinds of human bodily material, but some body parts are more in demand than others, and they are in demand for different reasons. Although such differences seem relevant to the appropriateness of payment, spelling out their moral import is not easy. It would seem that we must be able to not only measure and compare the size of the unmet demand for different body parts - a challenging task indeed - but also to determine and compare its moral weight. One important consideration here is that the demand for different body parts reflects interests of different kinds and of different parties. These include recipients' interest in survival or health (blood, kidneys), recipients' interest in procreation (gametes, uteri), patients' and pharmaceutical firms' interest in drug production (plasma), future patients' interest in new therapies (eggs), and researchers' and/or the general public's interest in scientific knowledge (eggs). Intuitively not all of these interests seem equally important to promote, yet it is not obvious how to rank them. The issue is further complicated by the fact that some body parts can be used to satisfy more than one interest. Eggs can be used for reproductive purposes as well as stem cell research, for instance, and such research can in turn be geared towards developing new therapies or advancing basic science.

Furthermore, the moral weight of the demand for body parts appears to partly depend on whether and to what extent that demand can be reduced or satisfied by alternative means. These means could be either "curative" (e.g. dialysis instead of transplantation for kidney patients, adoption instead of conception with donor gametes for infertile people) or "preventive" (e.g. avoiding kidney disease by reducing high blood pressure and diabetes,

\footnotetext{
${ }^{8}$ Since all potentially relevant pragmatic considerations cannot be covered in one paper my discussion will be selective. I will leave out concerns about exploitation, for instance. Although such concerns loom large in this context, they partly overlap with principled concerns of the kind discussed above and/or with the concerns about harm and consent discussed below, and when they do not overlap with such concerns it is unclear whether they support policies against payment (Wilkinson 2003). Also, my discussion of societal consequences will be limited to "crowding out" effects. There may well be other such consequences that matter to the legitimacy of payment, e.g. social and legal pressures on providers that the normalization of payment may create (Andrews 1986, Rippon 2014). But these effects are likely to vary between institutional and cultural contexts at least as much as between body parts, making them difficult to consider on the level of abstraction where my argument proceeds.
} 
avoiding infertility by promoting earlier family making). When such alternatives are nonexistent, unavailable, or clearly inferior, the demand for the body part seems, other things being equal, more compelling than when they are widely available and of comparable quality.

It seems presumptuous to try to derive a complete account of the moral import of the demand for different body parts and the implications thereof for the appropriateness of payment from these general observations. But allow me to suggest a cautionary note and a rough heuristic. The cautionary note: simple measures such as the length of waiting lists are insufficient for ethically assessing the demand for body parts. The heuristic: other things being equal, the greater the unmet demand for a body part, the weightier that demand, and the lower the prospect of reducing or meeting it by alternative means, the stronger the reason to seek to expand the availability of the body part by paying providers. Interestingly, from this perspective the case for incentives is arguably comparably weak in the context where they seem to be most widely used: reproductive donation. This is because there normally are other ways for infertile people of having children and because lives are not, after all, at stake.

\section{Harm to providers}

It might be thought that the potential harmfulness to providers gives us a simple criterion for distinguishing between body parts. The provision of different parts requires interventions that vary greatly in their invasiveness and potential complications - contrast sperm donation with living liver donation. Also, the long-term effects on providers' health may differ considerably between parts - contrast the quick replenishment of a pint of blood with life long dependency on a single kidney. Based on such considerations, it might be argued that payment is inappropriate in connection to body parts whose provision entails overall health risks above a certain level, but appropriate in connection to parts whose provision is less risky.

But this is too quick. Although the provision of different body parts involve very different levels of risk, these risks are generally considered acceptable when money is not involved. Unpaid living liver donation and unpaid sperm donation are both permitted, despite involving risks of very different magnitudes. And, as proponents of payment stress, the money itself does not add to the risk (Andrews 1986, Wilkinson 2003). So while health risks may provide a basis for determining which body parts may be procured from living providers at all - we do not permit living heart donation - they do not seem directly relevant for distinguishing the parts that may be provided in return for money from the parts that may not.

However, perhaps a more sophisticated appeal to health risks could justify such a distinction. Since risks and burdens differ greatly depending on what body part is provided, 
payments would also have to be set at different levels in order to effectively incentivize providers. More money is presumably needed to motivate somebody to donate a liver segment than to donate semen. It is conceivable that higher levels of payment predominantly attract providers of low socioeconomic status to a larger extent than lower levels of payment, i.e. that the poor would constitute a larger proportion of all paid liver donors than of all paid semen donors. It is also conceivable that these providers face larger health risks than better off providers (Koplin 2014). If both these assumptions are true, health risks to providers might justify distinguishing between body parts after all. The money does add to the risk of provision, in the sense that paid providers will be recruited from other groups than unpaid providers - groups that face greater health risks. And the money adds more to the risk (in this sense) when the payment is large. So we may want to allow payment only for body parts whose provision involves relatively small health risks and where the sums involved are low.

While some such argument might work, it is worth emphasizing that it rests on two empirical assumptions that require support. As to the first assumption, it is not clear that high payment for high risk attracts a larger proportion of poor providers than low payment for low risk. ${ }^{9}$ For all we know the opposite may even be the case: only the poor bother about small sums, whereas large sums, even when coupled with greater risks, motivate a comparatively larger proportion of well off providers. As to the second assumption, while it has been plausibly suggested that kidney providers who depend on manual labor and lack adequate nutrition and healthcare access may face greater long-term risks than better off providers, this suggestion remains speculative due to the lack of longitudinal studies on this group (Koplin 2014). Moreover, it is unclear to what extent similar disparities can be expected in regard to the provision of other body parts. It thus remains an open question whether concern about harm to providers' health allows us to distinguish between body parts.

However, it is possible that such distinctions could be drawn based on concern about another kind of harm. Several studies of illegal transnational kidney markets suggest that vendors are heavily stigmatized as a result of the sale (Lundin 2012, Tong et al. 2012). That is, on top of health risks (which are significant indeed in such markets), vendors are at risk of

\footnotetext{
${ }^{9}$ There seem to be no studies that directly compare socioeconomic profiles of paid providers across several different body parts and risk/payment levels, and available information on providers of specific parts does not admit of the generalizations and comparisons needed to support this assumption. While poor populations seem to be overrepresented among paid providers in certain settings (Naqvi et al. 2007, Cooper and Waldby 2014), it is unclear that they are (or would be) more overrepresented when the risk/payment is higher.
} 
social harm. It is possible that accepting money is more stigmatizing for providers of some body parts (e.g. kidneys) than for providers of other parts (e.g. blood). If so, there may be a harm-based rationale for allowing payment to providers of the latter kind but not the former.

There are, however, two difficulties here. First, as an empirical matter, it is no trivial task to estimate precisely how stigmatizing it is to accept money for a particular body part; nor are differences between body parts in this regard easily measured. These difficulties are especially salient in the case of body parts whose paid provision is currently prohibited, because the stigma may be (partly) a result of the prohibition itself. Second, even if social harms can be accurately assessed, we need to ask whether they should serve as a basis for protective policies in the same way as physical harm. On the one hand, there is something arbitrary about treating the two kinds of harm differently. From the point of view of the victim, social harms can certainly be equally serious and "real" as physical harms. On the other hand, stigma is the result of social norms that - at least in the present case - seem rather ugly. For instance, Moldovan kidney vendors are condemned as form of prostitutes (Lundin 2012). It might be argued that banning payment in order to protect providers from stigmatization expresses endorsement or at least tolerance of the questionable norms that underlie the stigma.

In sum, it remains unclear that considerations of harm to providers allow us to distinguish between body parts in regard to the appropriateness of payment. However, they may enable such distinctions indirectly, when coupled with considerations of consent. I now turn to that possibility.

\section{Consent}

I noted above that because the provision of different body parts involves different levels of risk and inconvenience, payment would also have to be set at different levels to effectively motivate providers. On the face of it, it seems plausible that these differences matter from the point of view of informed consent - i.e. that higher payment is more problematic than lower payment in this regard. If this is true, there is a consent-based rationale for distinguishing between body parts. I shall consider two arguments along these lines.

First, there is a widespread concern that payment to providers of bodily material and participants in research may constitute an "undue inducement" that threatens the quality of their consent. This concern is often raised specifically in regard to large payments. For instance, the CIOMS's research ethical guidelines state that: "Payments...to research subjects should not be so large as to persuade them to take undue risks or volunteer against their better 
judgment. Payments...that undermine a person's capacity to exercise free choice invalidate consent." (CIOMS 2002, 46) This quote suggests that not all payments but only payments above a certain level constitute undue inducement. If this reasoning is sound (and applicable to donation) it provides a rationale for distinguishing between body parts, permitting incentives only when risks and inconveniences are sufficiently small that only sums below this level are needed.

I say "if", because the notion of undue inducement is notoriously slippery and controversial. It is unclear in what way large monetary offers are supposed to threaten consent. One concern is that such offers might make providers overlook the risks involved in donation. However, the problem then is arguably not the money but the insufficient appreciation of the risks, which can in principle be remedied by adequate informational measures (Dickert and Grady 2008). Another concern is that large sums of money may be irresistible - too attractive to refuse - and so render the providers' consent insufficiently voluntary. But this is puzzling given that we do not usually deny that people can voluntarily accept large sums of money in other contexts, e.g. when offered well-paid jobs or lottery prizes (Wilkinson 2003). I am not suggesting that an undue inducement-based argument for distinguishing between body parts necessarily fails. The point is that it can only be as good as our best account of undue inducement, and that it is unclear what that account looks like. ${ }^{10}$

The second argument is less familiar but no less worth considering. Higher payment is obviously more attractive to providers than lower payment, other things being equal. But higher payment is also more attractive to other parties who may have an interest in the provider's money. There is evidence from illegal kidney markets and Iran's legal market that vendors are sometimes coerced or pressured to sell by moneylenders, family members, and employers who want the money from the sale (Zargooshi 2001, Goyal et al. 2002, Naqvi et al. 2007). It seems clear that the potential for this sort of illegitimate pressure is greater the higher the payment (again other things being equal). If this is right, there is a possible consent-based justification for distinguishing between body parts, independently of the

\footnotetext{
${ }^{10}$ Some believe that the real worry about inducement is not that it threatens consent but that it might encourage people to overcome their deeply held values. On this account, it is disrespectful to pay people to do things that they have strong objections against, even if the money does not impair their judgment or the voluntariness of their decision (Dickert and Grady 2008). This account is plausible, but it cannot be invoked in support of the argument considered here because it has nothing to do with the level of payment. It seems no less disrespectful to offer somebody a small sum for a pint of blood than a large sum for a kidney if that person has strong objections against donating both.
} 
question of undue inducement. We may want to allow incentives only in connection to body parts whose provision involves low levels of risk and inconvenience and where the payment therefore can be kept low in order to minimize the risk of third-party pressure on providers.

Although the potential for such pressure is a plausible reason to resist financial incentives in certain cases (Malmqvist 2014), it is notable that this potential is not a simple function of the size of the sum on offer. The form and timing of the payment are also likely to be relevant. Non-transferrable benefits like tax brakes and discounts on treatment are unlikely to attract coercers, and delayed cash transfers are presumably less attractive than immediate ones. The speed and ease with which a body part is procured probably matter too. A long and cumbersome procurement process with an uncertain result (e.g. egg donation) is potentially more discouraging to would-be coercers than a quick and easy process with a certain result (e.g. sperm donation) - though, of course, the higher potential payoff in the former case pulls in the opposite direction. Despite these qualifications, concerns about third-party pressure on providers do appear to provide some support for treating body parts differently. ${ }^{11}$

The size of the payment aside, it is possible that providers of different body parts find themselves in different circumstances with different implications for their capacity or opportunity to provide robust consent. For instance, egg donors' decision making might be affected by the stressfulness of their fertility treatment (Roberts and Throsby 2008), and intrafamilial kidney or liver donors might be subject to strong emotional pressure from relatives (Scheper-Hughes 2007). Based on such considerations it might be argued that it is inappropriate to offer financial incentives to providers who are in circumstances where consent is already difficult. However, this argument does not explain why money makes consent even more difficult in these circumstances. It presupposes some other, independent account of the effects of payment on consent - such as one of those considered already - and thus does not require separate discussion.

\section{Harm to recipients}

One recurrent concern about paying providers of body parts is that the payment may introduce risks to recipients. The idea is that would-be providers who seek financial gain have an incentive to hide potentially disqualifying medical information, in contrast to providers who

\footnotetext{
${ }^{11}$ This support would be strengthened if higher payment could be assumed to attract a larger proportion of poor providers than lower payment because the poor are likely to be especially vulnerable to such pressure (Malmqvist 2015). However, as we have already seen, this is an empirical assumption that has to be backed up by evidence that currently seems unavailable.
} 
have the recipients' interest at heart. This concern has been raised in relation to blood donation (Titmuss 1970) and kidney donation (Rothman and Rothman 2006), but in principle it applies more broadly. Can body parts be distinguished on such grounds?

On the face of it, the distinction between higher and lower levels of payment seems relevant here too. Other things being equal, one would think that more money (e.g. for a liver lobe) is more likely than less money (e.g. for blood) to motivate people to engage in behavior that exposes others to risks. But other things are not equal. Remember that insofar as payment is intended as an incentive to donate, larger sums seek to offset higher levels of risk and inconvenience. We can only assume that larger sums are more likely to induce providers to expose others to risk insofar as these sums are perceived as providing larger net gains, once these "costs" are counted. It is not clear that we can assume any such simple correlation.

Perhaps it is more promising to distinguish between body parts based on how large risks recipients run if medically unsuitable providers "slip through". This is a complex empirical question that cannot be definitively settled here. But I suspect that the size of this risk may have less to do with what specific body part is provided than with what procedures are in place for screening the parts or the providers. In other words, from the point of view of protecting recipients, the relevant ethical distinctions may be between different organizational arrangements rather than between different body parts as such.

\section{Crowding out}

Another recurrent worry about payment is that it might "crowd out" altruism. The idea here is that allowing payment for a good may change its social meaning in a way that discourages unreciprocated giving. It will easily seem pointless to give something away for free when you could get money in return. One version of this concern has been mentioned already: financial incentives might cause a decrease in the overall supply of body parts by discouraging unpaid donation. Since I assume that incentives are effective, I will not discuss this version further.

There is, however, another version of the crowding out concern. In his classic work on blood donation, Titmuss (1970) expressed worries not only about the effects of payment on the blood supply but also, perhaps more importantly, about its wider societal consequences. Whereas altruism is characteristic of close personal relationships (e.g. between friends and family), Titmuss noted that blood donation is a rare occasion for behaving altruistically towards unknown strangers. As such, he argued, it helps sustain a sense of solidarity on a 
societal level, beyond intimate relationships. Hence, since money discourages altruistic blood donation it also threatens to erode this general sense of solidarity. ${ }^{12}$

Interestingly, this hints at a rather different distinction between body parts than the one discussed earlier in relation to harm and consent. The concern about eroded solidarity makes sense in relation to non-directed donation, i.e. donation to unknown strangers. Such donation indeed relies upon the sort of impersonal, solidarity-promoting altruism that Titmuss highlighted. But this concern seems less pertinent to directed donation, i.e. donation between relatives and friends. Such donation does not invoke any generosity towards strangers but only the more usual and robust sort of altruism that characterizes close personal relationships. This suggests that, if we want to protect solidarity by preserving occasions for impersonal altruism, we should be more worried about introducing financial incentives in contexts where non-directed donation is widespread than in contexts where it is rare. From this perspective, paying blood, plasma, or sperm donors is more problematic than paying living organ donors contrary to what considerations of consent, risk, and payment levels suggest.

\section{Summing up}

In this section I have adopted a pragmatic outlook on distinguishing between body parts in regard to the appropriateness of payment in order to avoid the deep and divisive questions about human flourishing that a more principled outlook raises. But the pragmatic approach turns out to face challenges of its own. These are partly empirical: several of the pragmatic arguments involve factual claims that remain unsupported and that seem difficult to support. Other challenges are normative. Different pragmatic considerations have rather different implications for when payment is appropriate. For instance, considerations of consent suggest that incentives are more problematic in the relatively high-risk organ donation context than in the more mundane practices of blood, plasma, and sperm donation, whereas considerations of altruism or solidarity suggest the opposite verdict. Any policy that treats incentives for different body parts differently on pragmatic grounds would have to balance these and other potentially conflicting considerations against each other. This would ultimately raise questions of a rather more principled sort. What values matter more? Health, family-making, or societal solidarity? And whose interests are more important to promote or protect? Those

\footnotetext{
${ }^{12}$ I cannot here defend Titmuss' argument but only explore its implications for the question at hand. For a compelling explication and defence of this argument, see Archard (2002).
} 
of providers, those of recipients, or those of society at large? Some conception of distributive justice is clearly needed here. ${ }^{13}$

Note also that any distinction between body parts drawn on pragmatic grounds will be context-dependent and variable. The size of the demand for different body parts depends on different potentially changing population-level factors, e.g. disease prevalence and familymaking customs, and the moral weight of that demand may change as alternative ways of meeting it appear or disappear. Similarly, concerns about harm to providers (and thus indirectly about consent) may lose force as safer techniques for acquiring body parts develop, or gain force as new knowledge about e.g. long-term risks appears. Thus, a distinction drawn at a particular time and place may have to be redrawn later or drawn differently elsewhere.

\section{Conclusion}

Should we reason differently about paying providers of body parts for transplantation, reproduction, and research depending on what part is involved and, if so, why? If we try to distinguish between body parts on principled grounds we end up in deeply contested questions about the human good. If, on the other hand, we adopt a more pragmatic outlook we are bound to speculate and must perform difficult balancing between different kinds of value and the interests of different groups.

In view of these difficulties, it might seem tempting to abandon the attempt to distinguish between body parts in regard to the appropriateness of payment. We should then reason in the same way about all parts, i.e. either welcome financial incentives to providers in general or - which seems more likely given the general restrictiveness about money in this area - reject them across the board. My analysis appears to lend some support to the latter view insofar as it suggests that payment is never entirely unproblematic, regardless of which of the body parts currently used for therapy, reproduction, and research is involved.

However, my analysis might also be of some use to those who wish to continue the search for systematic, policy relevant distinctions between body parts. At least it hints at two different directions in which to take this search. Those who hold principled convictions about the special status of certain body parts should seek to articulate and defend the views of the good life that underlie these convictions. The more pragmatically minded should strive to make explicit and gather evidence for the empirical assumptions on which their arguments

\footnotetext{
${ }^{13}$ In principle any general such conception - utilitarianism, egalitarianism, prioritarianism, etc. - is applicable here. Determining which one is preferable in this context is beyond the scope of this paper.
} 
rely. I have identified some such assumptions that could, if properly supported, strengthen the case for distinguishing between body parts - e.g. the assumption that higher payment attracts a larger proportion of worse off providers than lower payment - but others are likely to remain implicit. The pragmatically minded must also consider which distributive principle should govern the weighing of different values and interests that their approach requires.

\section{Acknowledgements}

I thank Erica Haimes and Ken Taylor for the opportunity to present an early version of this paper at the $16^{\text {th }}$ PEALS International Symposium in Newcastle, UK, September 22-23, 2015, and other participants in the symposium for valuable feedback. I am also grateful to Lisa Guntram, Hanna Van Parys, András Szigeti, Martin Andersson, and two anonymous reviewers for this journal for helpful comments on later versions.

\section{References}

Almeling, R. 2011. Sex cells: The medical market for eggs and sperm. Berkely: University of California Press.

Andrews, L. 1986. My body, my property. Hastings Center Report 16(5): 28-38.

Archard, D. 2002. Selling yourself: Titmuss's argument against a market in blood. The Journal of Ethics 6: 87-103.

Aristotle. 1980. Nicomachean ethics. Trans. W.D. Ross, Oxford: Oxford University Press.

Beauchamp, T.L., and J.F Childress. 2012. Principles of biomedical ethics, $7^{\text {th }}$ ed. Oxford: Oxford University Press.

CIOMS (Council for International Organizations of Medical Sciences). 2002. International ethical guidelines for biomedical research involving human subjects. Geneva: CIOMS/WHO.

Cohen, C.B. 1999. Selling bits and pieces of humans to make babies: The gift of the magi revisited. Journal of Medicine and Philosophy 24: 288-306.

Cooper, M., and C. Waldby. 2014. Clinical labor: Tissue donors and research subjects in the global bioeconomy. Durham: Duke University Press.

Dickert, N., and C. Grady. 2008. Incentives for research participants. In The Oxford textbook of clinical research ethics, ed. E.J. Emanuel, C.C. Grady, R.A. Crouch, et al., 386-396. New York: Oxford University Press.

Eyal, N. 2009. Is the body special? Review of Cécile Fabre, Whose body is it anyway? Justice and the integrity of the person. Utilitas 21:233-35. 
Fabre, C. 2006. Whose body is it anyway? Justice and the integrity of the person. Oxford: Oxford University Press.

Gneezy, U., and A. Rustichini. 2000. A fine is a price. Journal of Legal Studies 29: 1-17.

Goyal M., Mehta R.L., Schneiderman L.J., et al. 2002. Economic and health consequences of selling a kidney in India. Journal of the American Medical Association 288:1589-92.

Harvey, J. 2015. Blood money: Is it wrong to pay donors? The Guardian, 25 January 2015.

Kant, I. 1997a. Lectures on ethics. Trans. P. Heath. Cambridge, U.K.: Cambridge University Press.

Kant, I. 1997b. Groundwork of the metaphysics of morals. Trans. M.J. Gregor. Cambridge, U.K.: Cambridge University Press.

Koplin, J. 2014. Assessing the likely harms to kidney vendors in regulated organ markets. American Journal of Bioethics 14 (10): 7-18.

Lundin S. 2012. Organ economy: organ trafficking in Moldova and Israel. Public Understanding of Science 21: 226-40.

Malmqvist, E. 2014. Are bans on kidney sales unjustifiably paternalistic? Bioethics 28: 110118.

Malmqvist, E. 2015. Kidney sales and the analogy with dangerous employment. Health Care Analysis 23: 107-21

Malmqvist, E. and Zeiler, K. 2016. Bodily Exchanges, Bioethics and Border Crossing: Perspectives on Giving, Selling and Sharing Bodies. London: Routledge.

Merleau-Ponty, M. 2002. Phenomenology of perception. Trans. C. Smith. London: Routledge.

Naqvi, S.A.A., B. Ali, F. Mahzar, M.N. Zafar, and S.A.H. Rizvi. 2007. A socioeconomic survey of kidney vendors in Pakistan. Transplant International 20: 934-939.

NCoB (Nuffield Council on Bioethics) 2011. Human bodies: Donation for medicine and research. London: Nuffield Council on Bioethics.

Nussbaum, M.C. 1992. Human functioning and social justice: In defense of Aristotelian essentialism. Political Theory 20: 202-246.

Nussbaum, M.C. 1995. Objectification. Philosophy and Public Affairs 24: 249-91.

Parfit, D. 1984. Reasons and persons. Oxford: Oxford University Press.

Pennings, G., J. de Mouzon, F. Shenfield, et al. 2014. Socio-demographic and fertility-related characteristics and motivations of oocyte donors in 11 European countries including supplementary file. Human Reproduction 29: 1076-1089.

Radin, M.J. 1996. Contested commodities: The trouble with trade in sex, body parts, and other things. Cambridge, Mass.: Cambridge University Press. 
Rippon, S. 2014. Imposing options on people in poverty: The harm of a live donor organ market. Journal of Medical Ethics 40: 145-150.

Roberts, C., and K. Throsby. 2008. Paid to share: IVF patients, eggs and stem cell research. Social Science and Medicine 66: 159-169.

Rothman, S.M., and D.J. Rothman. 2006. The hidden cost of organ sale. American Journal of Transplantation 6: 1524-1528.

Scheper-Hughes, N. 2007. The tyranny of the gift: Sacrificial violence in living donor transplants. American Journal of Transplantation 7: 507-511.

Svenaeus, F. 2012. Organ transplantation and personal identity: How does loss and change of organs affect the self? Journal of Medicine and Philosophy 37: 139-158.

Svenaeus, F. 2015. The lived body and personal identity: The ontology of exiled body parts. In Bodily exchanges, bioethics and border crossing: Perspectives on giving, selling and sharing bodies, ed. E. Malmqvist, and K. Zeiler, 19-34. London: Routledge.

Titmuss, R.M. 1970. The gift relationship: From human blood to social policy. London: Allen and Unwin.

Tong, A., J.R. Chapman, G. Wong, et al. 2012. The experiences of commercial kidney donors: Thematic synthesis of qualitative research. Transplant International 25: 113849.

WHO. 2010. Guiding principles on human cell, tissue and organ transplantation. http://www.who.int/transplantation/Guiding_PrinciplesTransplantation_WHA63.22en.p df

Wilkinson, S. 2003. Bodies for sale: Ethics and exploitation in the human body trade. London: Routledge.

Williams, C. 2011. Pay ban on donor organs doesn't include bone marrow, court says. Los Angeles Times, December 2, 2011.

Zargooshi, J. 2001. Quality of life of Iranian kidney “donors”. Journal of Urology 166(5): 1790-1799. 